\title{
MI-SPE, M-SPE AND M-SPD RECENT APPLICATION ON SOLID PHASE EXTRACTION FOR COMPOUND EXTRACTION OF COMPLEX MATRICES
}

\author{
SHARIMINA VENU GOPALAN, ALIYA NUR HASANAH
}

Pharmaceutical Analysis and Medicinal Chemistry Department, Faculty of Pharmacy, Universitas Padjadjaran

Email: aliya.n.hasanah@unpad.ac.id

Received: 06 Feb 2019, Revised and Accepted: 28 Mar 2018

\begin{abstract}
Solid Phase Extraction is a method used for extraction, purification of compounds contained in complex matrices and purification of samples in the fields of industry, pharmacy, and toxicology analysis. This review represents the recent advances of solid phase extraction from different mode of separation which are the most commonly used in recent days such as molecular imprinting solid phase extraction (MISPE), magnetic solid phase extraction (MSPE) and matrix solid phase dispersion (MSPD). In this review, the applications of MISPE in the analysis of agrochemicals such as herbicides, fungicides and insecticides are summarized. This review also states preparation of various magnetic composites (MSPE) based on graphene and its application as adsorbents in pre concentrating natural mixes, organic macromolecules. Besides this, this review summarizes the application of MSPD in biological, food, and environmental samples, including both organic and inorganic analyte.
\end{abstract}

Keywords: Solid phase extraction, Recent advances, Molecular imprinting solid phase extraction, Magnetic solid phase extraction, Matrix solid phase dispersion

(C) 2019 The Authors. Published by Innovare Academic Sciences Pvt Ltd. This is an open access article under the CC BY license (http://creativecommons.org/licenses/by/4.0/) DOI: http://dx.doi.org/10.22159/ijap.2019v11i3.32410

\section{INTRODUCTION}

A method utilized for extraction, sanitization of compounds contained in complex matrices and purification of samples in the fields of industry, pharmacy, and toxicology analysis is called strong stage extraction. It is the most generally utilized analytical extraction strategies and can facilitate the analysis of a compound from biological materials such as blood, urine, water, etc. which contain many matrices. The problem that often arises is when there is a sample whose composition is unknown but is very complex and contains so many chemical components in the form of liquid and the presence of solid particles that expand inside. Therefore, we need a technique that can analyze the specific compounds contained in a sample [1]

Solid Phase Extraction (SPE) is a relatively new methodology but SPE is fast developing as the main tool for sample pre-treatment or for clean-up of dirty samples, for example, samples that have high matrix content such as salts, proteins, polymers, resins, etc. Filtration, homogenization, precipitation, chemical reactions, solvent exchange, concentration, matrix removal, solubilization are components that can be used singly or in combination to obtain samples with forms that are compatible with the analysis tools needed [1]

SPE has the advantage when compared to liquid-liquid extraction that is by using SPE the extraction process becomes more perfect, the separation of analyte from the matrix becomes more efficient, reducing the organic solvents used. SPE is an efficient separation process so that high recovery ( $>99 \%$ ) is easier to achieve when compared to liquid-liquid extraction. In liquid-liquid extraction, several extractions are still needed to obtain high recovery, whereas with SPE only one-step is needed. Moreover, SPE has advantages and has been widely used because it can use various stationary phases, fast and simple procedures and high throughput. The main advantage of SPE is its easy use, fast time and generally only requires a small volume of extraction solvents [2].

To improve selectivity in sample analysis, the current SPE method are combined with other methods such as chromatography (GC-MS) UV-Vis Spectrophotometer, HPLC, Gas and Mass Chromatography. According to Barnes et al., the combination of chromatography and SPE can be used more simply and effectively in purification, sample analysis. The advantages when compared to other methods such as HPLC, NMR, and MS are low costs, the ability and sample analysis are quite good [2].

\begin{abstract}
Methodology
Our review is based on the literature obtained from the PubMed and Scopus databases using the keywords "molecular imprinted solid phase extraction", "matrix solid phase dispersion" and "magnetic solid phase extraction". The specific keywords related to application of molecular imprinted solid phase extraction, matrix solid phase dispersion and magnetic solid phase extraction used were "molecular imprinted solid phase extraction in complex matrices," "magnetic solid phase dispersion in food," "molecular imprinted solid phase extraction in biological fluid," and "matrix solid phase dispersion in pharmaceuticals. The following exclusion criteria were applied: reviews, opinions or commentaries, non-English language, and unrelated topics such as other type of solid phase extraction beside molecular imprinted solid phase extraction, magnetic solid phase extraction and matrix solid phase dispersion.
\end{abstract}

\section{Different mode of separatation}

The following are the frequently utilized method of detachment in solid phase extractions in current days dependent on the articles, for example, molecular imprinted solid phase extraction (MI-SPE), Magnetic SPE (MSPE) and matrix solid phase dispersion. In the new advancements of test readiness procedures, molecularly imprinted polymers (MIPs) have picked up enthusiasm as a novel sort of sorbent with alluring properties. Such polymers may move toward becoming supplement to antibodies to be utilized in pesticide assurance $[3,4]$. Magnetic solid phase extraction has been utilized as pretreatment procedure for the examination of a few mixes due to its points of interest when it is contrasted and great strategies. Magnetic solid phase extraction limits the utilization of additional steps, for example, precipitation, centrifugation, and filtration that diminishes the control of the example [5-77].

Uses of MSPD have secured natural, nourishment, and ecological examples, including both organic and inorganic analyte. Matrix solid phase dispersion (MSPD) has turned out to be a proficient example arrangement method for solid, semi-solid, and sticky examples [8].

\section{Molecular imprinting solid phase extraction}

The molecular printing technique enables synthetic polymers to be prepared for a template molecule with specific binding sites. This can be achieved if the target acts as a molecular template during the polymerization process. Monomers with functional groups are 
arranged by non-covalent or covalent interactions around the template. After copolymerization with cross-linking reagents, the functional groups are fixed in the polymer matrices in defined positions. After removal of the template by chemical cleavage or solvent extraction from the polymer networks, complementary binding cavities with size and shape are produced (fig. 1). Since MIPs contain binding sites "tailor-made," they have a high degree of selectivity and affinity for the template. These materials can be used in various fields, such as chemical analysis and detection $[9,10]$, separation and purification [11], drug delivery [12] and catalysis [13].

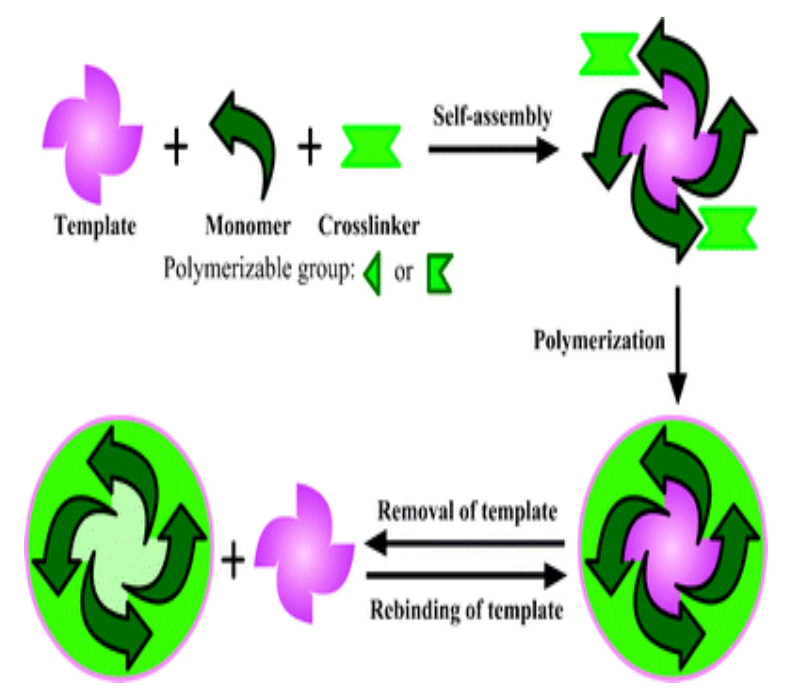

Fig. 1: Process of molecular imprinting [14]

Increasing the selectivity of SPE was done a great deal using the molecular imprinting polymer (MIP) technique, which combined this technique with the so-called molecular imprinting solid phase extraction (MI-SPE). Lately, molecularly imprinted polymers (MIPs) have made great influences in planned recognition capacity, stability relative simplicity and low readiness expenses, and potential application to a wide assortment of target molecules [15]. The utilization of MIP on SPE has a high advantage because it can selectively extract and eliminate the sample matrix in the analyte. MI-SPE has designs that follow natural mechanisms, such as specific antibody and biological receptor bonding mechanisms. MI-SPE is a versatile technique that enables biological and chemical molecules to be attracted [16].

\section{a) MISPE application in agrochemicals}

It has grown quickly in the region of agrochemical investigation recently. Nevertheless, just a single survey concerning the utilization of MISPE in agrochemical identification has been printed [17]. Latest analytical strategies require a high level of affectability to discover and measure agrochemicals. Some MIPs are combined through semicovalent impressions. Silica embedded with MIP is additionally cutting-edge as a sorbent for SPE [18].

\section{b) MISPE application in herbicides}

The extraction and affirmation of triazine herbicides from various examples have gotten significant consideration in molecular imprinted solid phase extraction. The separation of triazines from vegetables and soils are made through precipitation polymerization for the preparation of MIPs in utilizing propazine [19]. MIPs were additionally arranged utilizing cyanazine as a format [20]. Their investigation demonstrated that a blend of photosynthetic-based biosensors and a pre-fixation strategy utilizing MIP permitted the location of photosynthesis-hindering herbicides in water at the dimension required by the European community [21], arranged for the utilization of new MIP-covered strong stage micro extraction

(SPME) strands and connected them to check triazines in convoluted examples. The outcomes demonstrated that the prometryne MIP- covered strands had an extraordinary selectivity and liking to the seven triazines and that the affectability of the triazine assurance was clearly enhanced by the MIP-covered SPME-HPLC strategy [22], which incorporated a propazine engraved polymer utilizing acetonitrile or toluene as porogen. The chemical compound prepared to be broken down was the best introduction. At last, the MISPE procedure was utilized to clean water, soil and maize test separates and micellar electro kinetic chromatography (MEKC) was likewise used to decide the triazins [23]. Djozan et al., in order to extricate triazine rice, onion and tap water, solid SPME fiber was created dependent on MIP. GC and GC-mass spectrometry (MS) inspected this herbicide.

Additionally, molecular imprinted solid phase extraction was utilized to separate phenyl urea and antidiabetic medicate herbicides[24], to plan two non-indistinguishable MIPs utilizing linuron or isoproturon as formats for precipitation polymerization. Detachment of phenyl urea herbicides in carrot, potato, maize and pea test are removed using MISPE strategy by utilizing HPLC-bright (UV) at $244 \mathrm{~nm}$ [25]. Cacho et al., by utilizing fenuron or isoproturon as templates and acetonitrile or toluene as porogens, incorporated four distinctive MIPs dependent on methyl acrylic acid (MAA). The outcomes demonstrated that fenuron polymers and polymer were incredibly specific utilizing toluene as a porogen. MIPs were utilized in groundwater and soil tests as another material to separate phenyl urea [26]. Tamayo et al. blended and bundled MIPs in HPLC segments of stainless steel $(125 \times 4,6 \mathrm{~mm})$.

Finally, the ideal engraved segment was utilized specifically for the LC-UV screening of phenyl urea herbicides from vegetable example extricates at a low fixation level in under $10 \mathrm{~min}$ [27]. Tang et al. utilized BSM as a layout particle to set up a precipitation polymerization MIP. The MISPE strategy has been enhanced for sulfonylurea extraction in soybean tests and a high recuperation has been accomplished. MIP recuperations for nicosulfuron (NS), metsulfuron-methyl (MSM), BSM and tribenuron-methyl (TBM) were likewise contrasted with C18 SPE cartridges; the outcomes demonstrated that MIP recuperation esteems were $29.34 \%$ for NS, $24.37 \%$ for MSM, $46.03 \%$ for BSM and $5.01 \%$ for TBM [28]. She et al. incorporated MIP for precipitation polymerization sulfonylurea herbicides utilizing chlorsulfuron as the template particle. The MIPs have been packed into cartridges. The LC-Tandem Mass Spectrometry (MS-MS) dictated the examples after extraction. MISPE was likewise utilized for different kinds of herbicides. A procedure dependent on chemical measurements and quantum science was proposed by [29] for the structure and blend of engraved polymers of sham chloroacetamide. Metolachlor deschloro has been picked as the layout. MISPE indicated specific restricting properties for chloroacetamide herbicides contrasted with business SPE sections and the lattice impact was altogether reduced [30]. Baggiani et al. arranged polymers of bentazone utilizing noncovalent polymerization of atomic impressions. The MIPs were sectioned in HPLC. The sections indicated great recuperations (91$96 \%$ ) and the convergence of 3.2-15.2 components.

\section{c) MISPE application in pesticides}

The utilization of MISPE for pesticide extraction and assurance has gotten a lot of consideration because of the wide circulation of pesticides in plants. Organophosphorus pesticides are generally utilized in agribusiness, as creepy insects and weeds can be controlled effectively to enhance the productivity and nature of the item. Regardless, their deposits may stay in the outcome of recuperation or capacity. The advancement of a touchy location system is critical to keep up these uncontrolled impacts on human prosperity and natural contamination.

Pereira et al. incorporated a MIP that could explicitly expel fenitrothion (FNT) from tomatoes. The clean-up and convergence of FNT before the HPLC examination was done with three separate MIP cartridges and a fortress measurement of $5 \mathrm{~m} \mathrm{~g} / \mathrm{g}$ for three days. The MIP presented 59\% medium extraction profitability. This MIP can be reused a few times after recuperation [31].

Another MIP course of action by utilizing a mix of trichlorphone and monocrotophos as a blended design. Another strategy for MISPE 
joined with GC for the affirmation of organophosphates in vegetables was created utilizing this engraved polymer as the sorbent [32]. This was fused by a room temperature ionic liquid in the graved polymer meddled with a mass polymerization technique utilizing dichlorvos as the configuration. The cartridge has been squeezed to pretreat vegetables with MIPs. This cartridge has been differentiated with the fragment of the C18 extraction [33]. The results from the chromatograms displayed that the engraved cartridge had a higher obsession affect and favored selectivity for dichlorvos over the C18 extraction area [34] Kang et al. organized a MIP by using diethyl(3-methylureido) (phenyl) methyl phosphonate (DEP) as a fake design by precipitation polymerization.

They found that explicit acknowledgment was basically dependent on the gathering of the investigator with the DEP-MIPs [35]. Xie et al. composed a precipitation polymerization MIP utilizing triazophos (TAP) as a design. In their work, a TAP-confirmation sensor for MIPchemiluminescence (CL) was created utilizing TAP-graved particles as acknowledgment segments and the lumionl- $\mathrm{H}_{2} \mathrm{O}_{2}$ CL reaction as the recognizable proof structure. The outcomes demonstrate that this procedure can be utilized for the online enhancement and area of residual organophosphate pesticides.

MISPE was additionally associated with different bug sprays, for example, pyrethroid and pirimicarb, for example [36]. Shi et al. utilized deltamethrin and cypermethrin as course of action particles (D-MIPs and C-MIPs) to orchestrate two sorts of MIPs. The outcomes demonstrated that the C-MIP-subordinate MISPE methodology indicated higher extraction recuperations and the proposed MISPE strategy joined with the GC-electron get identifier(ECD) was utilized viably to guarantee pyrethroid in ocean water. Differentiated and the customary Florisil SPE, their MISPE demonstrated more prominent productivity of separation and less utilization of common dissolvable [37]. Zhou et al. consolidated a sub-atomic stone landmark utilizing in situ polymerization utilizing pirimicarb as a format, MAA as a monomer, ethylene glycol dimethyl acrylate as a cross-linker and a toluene-dodecanol mix as a porogenic dissolvable. Another system for the sensitive, explicit affirmation of pirimicarb in tomato and pear has been created by solidifying littler scale extraction of MIP-polymer stone landmark with HPLC-photodiode display (PDA). They likewise analyzed the execution of MISPE and C18. The higher cleanup proficiency utilizing MISPE was appeared in the chromatogram and the MIP stone landmark could typically be reused without debilitating.

\section{d) MISPE application in drugs}

In recent decades, drugs classes such as antibiotics and beta blockers are widely used in the application of MISPE. Macrolide (MAL) is an antibiotics used in the water pollution. As a durable and highly specific SPE material, the molecularly impressed polymer (MIP) can overcome the aqueous matrix's influence to enrich ultratrace amounts of target compounds. It is possible to use MISPE to separate and enrich numerous pharmaceuticals from environmental water, such as herbicides [38], phenolic compounds [39], pesticides [40] and hormones [41]. It is more practical to prepare an MIP that can selectively enrich multiple structural analogs due to the multiple antibiotics in water samples. MALs should be monitored in the long run as one group of the largest consumption of antibiotics in animal husbandry. A novel LC-MS/MS method was developed based on the MISPE to analyze the macrolide drugs in different water sources. The MISPE cartridge shows higher recognition capability towards macrolides compared to traditional SPE cartridges and can be recycled more than 20 times. The application of the method developed in real water samples has demonstrated its feasibility and practicalityBesides this, atenolol as a class of beta blockers is not only being used in the treatment of hypertension, cardiac arrhythmias, myocardial infarction and angina pectoris but also as doping for athletes due to its effectiveness in heart rate, anxiety and tremors [42]. MIP-SPE sorbents's ability to recognize analyte targets is influenced by the nature of the template, monomers and reactions in them [43]. Previous studies have been conducted using methacrylate acid (MAA) as a functional monomer to synthesize sorbent MIP-SPE atenolol [42]. In this study, MI-SPE atenolol sorbent was made from itaconic acid as a functional monomer with methanol as a porogen by bulk polymerization method so that after its adsorption characteristics are identified it can be used as an alternative method of selective sample preparation of atenolol from the blood sample.

\section{Magnetic solid phase extraction}

A method that has been considered significantly in the examination of compounds in feeing tests are called magnetic solid phase extraction (MSPE). MSPE depends on the extraction of various compound from the example utilizing solids with attractive properties. This procedure can be envisioned as an attractive partition regularly used to isolate attractive stages from nonmagnetic stages [44]. The straightforwardness of this strategy affects the advancement and utilization of partition methods including the utilization of attractive fields.

This procedure comprises in the amalgamation of particles with attractive properties (for the most part magnetite Fe304) trailed by a covering of the attractive stage with various natural mixes. The changed solids are connected as adsorbents amid detachment, division, and pre grouping of the analyte [45-47]. The MSPE depends on the scattering of an attractive adsorbent in arrangement. The attractive adsorbents with the analyte adsorbed superficially can be disconnected and eluted with the expansion of fitting solvents. The methodology does not require extra advances, for example, centrifugation, precipitation, or filtration of the example.

MSPE method has been utilized for these perceived advantages, for example, effortlessness, productivity, cost, and high selectivity. This method utilizes the utilization of outer attractive field in the segregation of the attractive particles in the detachment and examination of various kinds of mixes with the fundamental target of discrete analyte of extensive volume without extra advances that could cause loss of analyte [48-50], since its disclosure has gotten significant consideration in the improvement of a few applications in the division of assorted analyte.

The blend by co precipitation is the strategy, which is increasingly connected to the combination of the attractive stage. Attractive solids can be covered with antibodies, explicit receptors, embodying of attractive particles with organic operators, polymers, and silica adjusted with various practical gatherings [51-53]. Extra impacts of their physical and compound attributes must be considered amid the plan of MSPE based philosophy.

In the nourishment territory MSPE has been connected to separation and specific pre centralization of proteins [54], metal particles [5561] and natural mixes, for example, anti-infection agents, pesticides, colors, phenolic mixes, and advertisers developing that are available in a few food stuff tests [49, 62-57].

\section{Detection of organic pollutants}

\section{Pesticides}

In the assurance of agriculture harvests against weeds, pests and infections, pesticides are probably the most vital instrument. Anyhow, the application of pesticides is extensive to the point that pesticide buildups can be often times found in consumer goods such as plants or creature beginning, natural compartments such as ecology, air, bodies of water, and soil. Organophosphorus pesticides, organochlorine pesticides, pyrethroid pesticides, carbamate pesticides, neonicotinoid bug sprays, benzoylurea bug sprays, triazole fungicides, imide fungicides and triazine herbicides are frequently used pesticides. The majority of pesticides have a place with ring structures based on carbon. In addition, G-based attractive composites have a comprehensive application as adsorbent to MSPE for the pesticide assurance buildups and it had been constantly created to acquire progressively viable, natural neighborly and specific investigative techniques. The most well-known adsorbent for their readiness techniques is MGC as it is faster, basic and more practical than those of different materials [68] are.

\section{Drugs}

Medication deposits investigation is made out of the examination of human and veterinary medications. Human and veterinary medications were done with buildup examination. Example of human 
medications are anti-microbial, pain relieving, mitigating, antidepressants, and antipsychotics, which includes two perspectives. Firstly, the outlandish outflows of healing facilities. Secondly, industrial facilities, and the medications staying in the human bodies, metabolites, and fecal matter. Whereas, example of animal medications are sulfonamides, antibiotic medication, and quinolones. Centers around the medications stays in the creatures' bodies, metabolite, and fertilizer. Earth, plasma, blood, and pee was given the low focus dimensions of medications, sufficient example pretreatment strategies for the evaluation of medications is basic. In the medication buildup investigation, G-form attractive composites were broadly utilized. Adding on, the attractive G/GO composites have incorporated different distinctive functionalities to accomplish higher extraction efficiencies and reduced LODs. By utilizing porphyrin-functionalized nanocomposite Fe304-graphene oxide (TCPP/Fe304-GO) as an adsorbent for sulfonamide (SA) detection in ecological water tests, there is rapid progress and productive pre-focus approach. It has been shown that Fe304-GO, TCPP/Fe304-GO showed a higher adsorption limit through the gusto-stacking connections and electrostatic connections between the decidedly charged SAs and the adversely charged porphyrin Fe304-GO functionalized [69].

\section{a) Detection of biological macromolecules}

Peptides [71] and proteins [70], a biological macromolecules associated with the diagnosis of disease have always received a wide and current interest. Due to its unique advantages, the MSPE system has as of late been broadly utilized in the seclusion and preconcentration of organic macromolecules.

Phosphorylation is a standout amongst the most widely recognized structures post-translational types of protein alteration, and it can direct cell exercises, for example, cell proliferation, cell regulation, transformation, metabolism, differentiation, signal transduction and cell regulation. The direction of organic pathways in cancer cells is critical for protein phosphorylation. It is in this way fundamental to build up an examination for the identification of phosphoprotein. $\mathrm{Lu}$ and associates built up the MSPE-based Fe304/graphene/TiO2 strategy for the extraction and advancement of phosphopeptides from organic examples. Changing the TiO2 graphene with high particular adsorption is one of the advancement from the article [72].

Yin et al. stated that an easy method of preparation for the twofold sided mesoporous nanocomposites attractive graphene (mag graphene@mSiO2) and after that utilized the mag graphene@mSiO2 to selectively enrich and analyze endogenous peptides [73]. It has a large surface territory and an extensive pore volume. The hydrophobic inward pore dividers could productively adsorb target particles through hydrophobic-hydrophobic communication. The Fe304 particles on the two sides of the materials could then disentangling the advancement procedure, which was fundamental for the treatment of complex natural examples.

New hydrophilic polydopamine-covered attractive graphene nanocomposites (MG@PDA) have been incorporated and utilized for the exceptionally effective tryptic immobilization [74]. The MG@PDA nanocomposites also made the nanocomposites Able to immobilize high amounts of trypsin yet in addition great hydrophilicity of PDA, which enormously enhanced biocompatibility of nanocomposites. The work manufactured a solid establishment for the high-throughput proteome research. Presently, the Sun group built up a powerful partition strategy to distinguish low endogenous phosphorylated peptides [75].

b) In this investigation, adsorbents chose were size-exclusive magnetic graphene/mesoporous silica composites with titanium (IV)-removed pore walls (alluded to as Ti4empe-MGMS). The presentation of hydrophilic polydopamine abbreviated the engineered procedure of Ti45-0-MGMSs and the arranged mesoporous channels supported the particular catching of endogenous phosphopeptides while precluding vast proteins.

\section{Detection of inorganic pollutants}

Heavy metal pollution is one of the world's most important environmental problems today. Even at extremely low concentrations, it is highly toxic and can hoard in living things, triggering a series of serious illnesses and disorders. The advancement of new adsorbents with a phenomenal adsorption limit is a standout amongst the most essential answers for the issue. G-based MSPE is becoming more and more popular in heavy metal isolation and enrichments such as Cd (II) [76], Zn (II) [77], As (III) and As (V) [78], Hg (II) [79], and Cr (VI) [80]. Cation connections, electrostatic collaborations, hydrogen bonds and dative bonds in the G-based attractive composite can consume metal particles. The $\mathrm{pH}$ of test arrangements affects the adsorbent's adsorption proficiency because the zeta capability of the attractive G/GO composite changes with the $\mathrm{pH}$ test. Zhou and partners demonstrated that an aqueous self-get together methodology could be utilized to combine the diminished graphene oxide/Fe304 composites and to quickly remove $\mathrm{Cr}(\mathrm{VI})$ from the composites [81].

It also showed rapid $\mathrm{Cr}(\mathrm{VI})$ evacuation with a high adsorption limit in corrosive and nonpartisan arrangements, while the expulsion productivity in soluble media diminished forcefully. This wonder was ascribed to the adjustment in control type and thickness of the adsorbent just as the current type of $\mathrm{Cr}(\mathrm{VI})$ with the example $\mathrm{pH}$. Adsorption was also non-selective even if both Fe304 and RGO were able to adsorb $\mathrm{Cr}(\mathrm{VI})$. The composite Triethylenetetramine-magnetite reduced graphene oxide (TETMRGO) has been synthesized and used for $\mathrm{Cu}(\mathrm{II})$ removal to improve selectivity [82]. The TET-MRGO composite demonstrated a high selectivity and adsorption limit (209.1 mg g-1) towards Cu (II) particles to the benefit of the high liking between nitrogen molecules and $\mathrm{Cu}$ (II) ions [83].

Zero valent iron is a strong adsorbent with a specific limit of adsorption. By altering with zero valent iron, it is conceivable to upgrade the adsorption limit of attractive G. An attractive G, for instance nanoscale zero valent iron/G $(\mathrm{OFG})$ composite, was along these lines arranged, portrayed and used to remove $\operatorname{Co}(\mathrm{II})$ from aqueous solution [84]. Zero valent iron showed a high adsorption capacity $(134.27 \mathrm{mg} \mathrm{g}-1)$ towards Co (II) ions at $30{ }^{\circ} \mathrm{C}$. Graphene nanocomposites (CoFe204-G and NiFe2O4-G) together with magnetic cobalt and nickel ferrites ( $\mathrm{CoFe} 2 \mathrm{O} 4$ and NiFe204) were blended through a solvothermal procedure and used to expel lead ( $\mathrm{Pb}(\mathrm{II})$ ) and cadmium (Cd (II)) particles from aqueous arrangement. [85].

The outcomes demonstrated that material sorts affected the adsorption limit. Qi et al. arranged three sorts of magnetite/decreased graphene oxide (MRGO) nanocomposites to find out if the preparation methods affect the capacity of adsorption examples are such as, solvothermal, hydrothermal and co-precipitation methods [86]. The results showed difference in surface functional groups, crystal structure, particle sizes, surface morphology and surface charge. These nanocomposites showed different performance in the adsorption of drugs, colors also, metal particles. The MRGO arranged by the co-precipitation steps demonstrated an extraordinary capacity to adsorb non-positive particles. Notwithstanding, those integrated by the solvothermal steps gave the others the best extraction limit and reusability and offered a decent prospect of attractive strong stage extraction. Hence, utilizing the correct readiness technique before application is profoundly prescribed to achieve the best extraction execution. In this way, it is profoundly suggested to use the right preparation method before application to achieve the best extraction performance.

\section{c) MSPE applications of graphitic carbon}

G-C3N4 is the most current 2D carbon material that is presently accepting extraordinary consideration in many research regions. From the explanatory outlook, due to its similitude to GN, great similarity with watery stage and expectable extraordinary fondness for a wide scope of mixes make g-C3N4 an exceptionally encouraging sorbent [87]. The simplicity of planning and minimal effort of the forerunners are without a doubt extra focal points appeared by this carbon material, that without a doubt can be procured by thermally impelled mass development or pyrolysis of melamine or urea [87-90, 91-92] likewise with no requirement for added substances such natural solvents [90]. It is clear that this foundation represents the extraordinary probability of g-C3N4 as sorbent for condition benevolent SPE [87].

The primary experiment for pre-fixation intentions are quite recent. These give an account of the use of g-C3N4 as SPME and SPE sorbents 
[89], [90] and unquestionably are making ready for application in MSPE. Surely, concerning GN, the g-C3N4 sheets can be advantageously beautified with attractive particles, along these lines anticipating reconglomeration and empowering quick detachment from the arrangement [91]. The work by [89] examined g-C3N4-SPME for extraction of test blends of different structure and furthest point, for example amphetamine, nerolidol, ametryn, deltamethrin, dodecane, and acryl-amide. It was uncovered that g-C3N4 was doing greater as far as extraction capacity plus strength contrasted with business filaments because of its extraordinary properties, predominantly free structure and multi type communication, combining hydrophobic impact, $p-p$ stacking, hydrogen holding and dipole-dipole. Now g-C3N4 has been tried likewise in the in-clump SPE mode to decide benzoylurea pesticides in juices [90]. The things were arranged by buildup of urea that yielded a nano-vessel shape like the human veins, prepared to do great extraction productivity and reusability.

Wang et al. [91] arranged an attractive g-C3N4 nanocomposite for pre-grouping of phthalate esters from water, explicitly di-n-butyl phthalate, butyl phthalate, dihexyl phthalate, and di-(2-ethyl hexyl) phthalate. The attractive things arranged by precipitation technique in nearness of melamine-determined g-C3N4, showed a sheet shaped with $\mathrm{Fe} 3 \mathrm{O} 4$ nanoparticles on the g-C3N4 base. Their hydrophobe and $\mathrm{H}$ bond held the analyte. Quantitative extraction (up to 99\%) was gotten in ten minutes, also the sorbent demonstrated to keep up its execution for successive MSPEs.

A similar combination was as well revealed for the MSPE of phenolic acids (three, 4-dihydroxybenzoic acid, 3, 4-dihydroxycinnamic acid, (2E)-3-(4-hydroxy-3-methoxyphenyl) prop-2-enoic corrosive) is removed by watery plant [88]. It explained that the sorption limit was not just administered by hydrophobe, but rather likewise by $\mathrm{p}-$ p stacking, hydrogen holding and electrostatic collaborations. The analyte was measured separated from the example and reusability was exhibited for five revolutions, focusing on the probability of gC3N4 likewise in lattices more not able to be predicted than water, and in concurrence continuously [92] concentrating on MSPE of PAHs from eatable fat tests.

Nevertheless, of the blended mode conduct of g-C3N4, its selectivity can be tuned by synthetic change of the immaculate structure. For instance, carbon self-doped g-C3N4 can be effectively acquired by using melamine pre-treated with ethanol as the forerunner and, in the meantime, oneself doping process yields a permeable object [93]. Development of delocalized $p$ bonds that would expand the fondness for fragrant atoms by the substitution of spanning $\mathrm{N}$ particles with $\mathrm{C}$ iotas. This can be extremely supportive in connection with the science of the analyte to be pre-concentrated, as in fact was accounted for by [91] for MSPE of five BFR (polybrominated phenyl ethers). The last appealing composite contained ca. 30 wt.\% of doped g-C3N4 interfaced with $\mathrm{Fe} 304$ particles (surface zone $100.7 \mathrm{~m} 2 \mathrm{~g} 1$ ) that for this circumstance accept similarly an important activity in favoring the dispersibility of the carbon-material in the liquid game plan (C-doped g-C3N4 is point of fact more hydrophobic than unadulterated g-C3N4). Mix and extraction are schematically defined in fig. 2 .

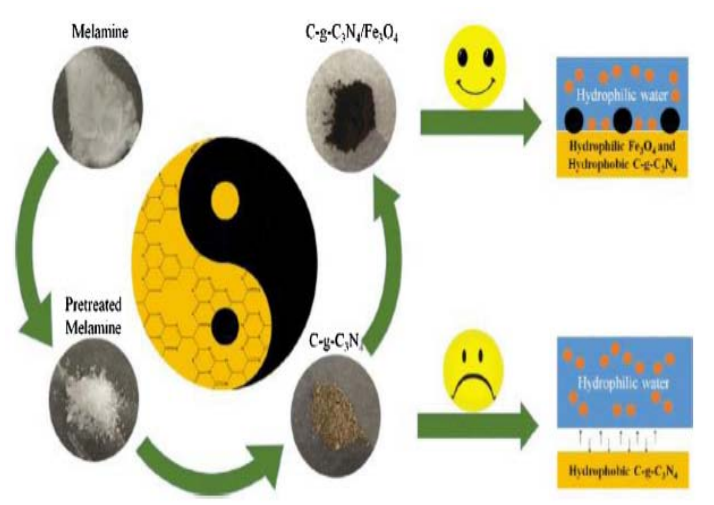

Fig. 2: Synthesis scheme of Fe304/C-g-C3N4 and extraction mechanism proposed for brominated [91]
In divergence to the pure material [88], $\mathrm{C} \sim$ doped g-C3N4 showed an extended sorption limit as per mixes hydrophobicity, featuring the job of selectivity tuning instigated by C-doping. The material was attempted in environmental waters, for example, tap and lake waters surrendering recuperation to $100 \%$, and was reused for adsorption/desorption cycles with unaltered extraction capacity.

From this, obviously novel performing materials basing their sorption properties to g-C3N4 are at present under scrutiny for various example arrangement systems (SPME, SPE, and MSPE). The starter reports show that the high profitability of this new carbon material could impressively augment the utilization of MSPE, in watery as well as in organic grids. Therefore, countless reports are normal sooner rather than later.

Graphene oxide (GO), the oxidized graphene derivative, is accessible by natural graphite powder oxidation [94]. On its nanosheet surface, GO contains abundant reactive oxygen functional groups in the form of epoxy, hydroxyl, and carboxyl groups, making it extremely hydrophilic and highly dispersive [95, 96]. This makes it difficult for graphene oxide to separate from aqueous solution directly. Preparing magnetic GO composite is a superior choice to overcome these problems, which can ensure convenient magnetic separation after adsorption.

The application based on magnetic GO in the preparation of samples to adsorb trace analytes has also received increased attention over the past few years [97, 98-100]. In this study, we synthesized magnetic $\mathrm{Fe} 304$ graphene oxide (Fe304/GO) as an adsorbent for the extraction, pre-concentration and determination of three commonly used chemicals (bisphenol A, naproxen, and triclosan) frequently detected in wastewater. Removal of toxic heavy metals from wastewater achieved primarily through multiple processes such as cloud point extraction, precipitation/co-precipitation, extraction of liquid and solid-phase extraction (SPE) [101].

There is also a study of (MSPE-DLLME) which has been developed for the strong desire/formal decision about something of biphenyl and biphenyl oxide in water samples. In this dispersive liquid-liquid microextraction (DLLME) technique, associate applicable mixture of extraction and disperser solvents is employed. This technique has attracted lots of attention because of its blessings, like short extraction time, low consumption of organic solvent, and ease. In this study, the surface of Fe304 nanoparticles was coated with polypyrrole as a conductive polymer. Using magnetic solid-phase extraction (MSPE), the analytes were extracted from the water samples followed by dispersive liquid-liquid microextraction. The effect of major factors were studied, including sorbent quantity, extraction time, type of elution solvent, volume of elution solvent, type of extraction solvent, volume of extraction solvent, and desorption time [102-104].

\section{Matrix solid phase dispersion (MSPD)}

Matrix solid phase dispersion (MSPD), first presented by [105] gives an elective way to deal with decrease dissolvable use and examination time for planning strong, semi-strong, and gooey examples [106]. In a run of the mill MSPD methodology, tests are mixed with sorbent to get homogeneous blend. The subsequent blend is moved and pressed into an extraction segment. At that point dissolvable is gone through the section to complete washing and elution venture for the extraction and seclusion of analyte from the framework. An extra co-sorbent could be stacked at the base of the section to additionally tidy up the eluent for some situations largely; the last concentrate can be breaking down by chromatography based systematic strategies. The traditional dissolvable extraction strategy, MSPD kills ventures of rehashed centrifugation and additionally filtration, and techniques of reextraction during comparison.

Solid phase extraction (SPE) is different, in which isolated dissolvable extraction strategy is required to make strong examples reasonable for stacking into a SPE section, MSPD kills the dissolvable extraction step. The utilization of dissolvable and accordingly the required control time for the arrangement would significantly downsize it. The patterns and improvements of MSPD [106, 107, 108-113] has serious audits identifying it. In this research, we center consideration on the most recent improvements in MSPD sorbent, 
scaling down of MSPD, on-line/in-line systems, and the adjustment of unique MSPD technique. Literary works amid 2015 and June 2018 are researched to keep away from the cover with later great audits $[112,113]$.

Shortly, MSPD extraction (MSPDE) was performed by mixing ox-like tissues with a proper measure of lipophilic strong stage pressing material $(\mathrm{C} 18)$ in a glass mortar with a glass pestle, to create a semidry, evidently homogeneous, simple to deal with material [105] in the Barker's fundamental work. At that point, the got powder was stuffed into a typical syringe barrel SPE section, from which target mixes were segregated with an appropriate elution dissolvable. Truth be told, the mixing of test with a rough strong help permitted the mechanical interruption of the grid structure, as affirmed by checking electron microscopy perceptions [108]. The fundamental paces of the procedure is effectively depicted profoundly somewhere else $[105,107,108,114]$ are accounted for in fig. 3.

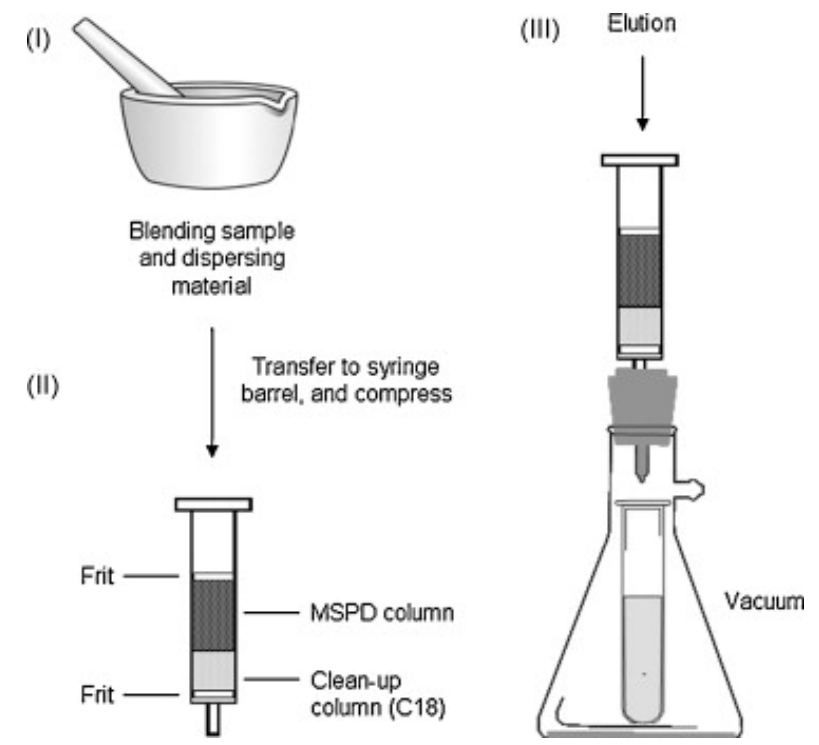

Fig. 3: Procedure of matrix solid phase dispersion

\section{Recent advances in MSPD sorbent}

Molecularly imprinted polymers (MIPs), the manufactured sorbents that show particular official of target sub-atomic, have been broadly used for the extraction of explicit mixes $[115,116]$. Sorbent requires to be mixed with test to get homogeneous blend in MSPD. Engraved polymers can be integrated utilizing different sorbents as bearer to enhance mechanical quality of MIPs materials. For instance, MIPs were set up on carbon nanotubes (CNTs) for the MSPD readiness of malachite green in amphibian items [117]. Silica gel [118], silica nanoparticles [119], and mesoporous silica [120] equally have been accounted for as the bearer of MIPs to improve the selectivity of MSPD sorbents. In addition, Wang et al. explained the combination of blended layout MIPs for the extraction of multi-class veterinary medications [121]. This impressive MIPs sorbent was used for the concurrent MSPD extraction of 20 sedates in meat, including 8 fluoroquinolones, 8 sulfonamides and 4 antibiotic medications.

Graphene is one of the carbon-based nanomaterials, which demonstrates extraordinary guarantee in test readiness [122, 123]. Graphene gives substantial surface region and Nano sheet morphology for enhancing adsorption limit. Likewise, the delocalized $\pi$ electron framework in graphene could make it shape solid $\pi$-stacking collaboration with mixes containing fragrant rings. These properties make graphene a decent possibility for the adsorption of benzenoid mixes. Sun et al discovered that a graphene-embodied silica sorbent for the investigation of flavonoids in the leaves of Murraya paniculata (L.) Jack [124]. Immobilized on the of surface of silica gel kept away from the collection and kept up the huge surface territory and $\pi$-electron rich structure graphene amid the mechanical mixing. Contrasted and five sorbents (graphene, silica gel, C18, diatomaceous earth, and unbiased alumina), graphene-typified silica demonstrated a better extraction efficiency for the objective flavonoid mixes.

Tan et al. planned Phenyltrichlorosilane for the extraction of polycyclic aromatic hydrocarbons (PAHs) in soils. [125]. this material adventures the high liking between magnesium oxide and PAHs to upgrade the maintenance of target atoms. Joining the microspheres with phenyltrichlorosilane reduced the focused adsorption of chlorinecontained obstructions, which are broadly exist in soil tests. Using hexane and DCM as flushing and eluting dissolvable, separately, seven PAHs were effectively decided in HPLC-FLD with breaking points of identification (LODs) of $0.02-0.12 \mu \mathrm{g} / \mathrm{kg}$.

Wang et al. mentioned that the usage of polyethyleneimine (PEI)changed attapulgite material as MSPD sorbent was considered for the guarantee of cadmium in fish items [126]. Presenting of PEI, which is a cationic polymer with high partiality to cadmium particle, brought about the high recovery of target particle in complex networks. High grouping of HNO3 (half, v/v) was compulsory to discharge the cadmium. Controlled by nuclear ingestion spectrometry (AAS), the LOD of cadmium in fish test was observed to be $2.5 \mu \mathrm{g} / \mathrm{kg}$. Moreover, sorbents, for example, mussel shell $[127,128]$, atomic strainer $[129$, 130], microcrystalline cellulose [131], and metal-natural system materials $[132,133]$ additionally have been considered.

\section{CONCLUSION}

In conclusion, SPE is a well-established technique and, its benefits over alternative sample preparation techniques, has been widely used for the analysis of diverse very different categories of compounds during a style of matrices. Moreover, SPE is essentially used for determination of natural pollutants in binary compound

Ecological examples because of an outsized sample volume may be utilized. In Addition, SPE is also used extensively in medical specialty and pharmaceutical analysis and within the analysis of food and beverages. The introduction of latest solid phases and additional selective activity modes, the development of latest experimental configurations to adapt SPE to specific things and therefore the improvement of automatic devices can lead to their application in numerous fields of qualitative analysis.

\section{AUTHORS CONTRIBUTIONS}

All the author have contributed equally

\section{CONFLICT OF INTERESTS}

\section{Declared none}

\section{REFERENCES}

1. Thurman EM, Mills MS. Solid phase extraction: principles and practice. John Wiley and Sons Inc. New York; 1997.

2. Simpson, Nigel JK. Solid-phase extraction: principles, techniques, and applications. New York: CRC Press; 2000.

3. Siemann M, Andersson LI, Mosbach K. Selective recognition of the herbicide atrazine by noncovalent molecularly imprinted polymers. J Agric Food Chem 1996;44:141-5.

4. Andersson LI. Molecular imprinting: developments and application in the analytical chemistry field. J Chromatography B 2000;745:3-13.

5. Safakoriva M, Safarık I. Magnetic solid-phase extraction. J Magn Magn Mater 1999;194:108-12.

6. Aguilar Arteaga K, Rodriguez JA, Barrado E. Magnetic solids in analytical chemistry: a review. Anal Chim Acta 2010;674:157-65.

7. Sharifabadi MK, Saber Tehrani M, Waqif Husain S, Mehdinia A, Aberoomand Azar P. Determination of residual nonsteroidal anti-inflammatory drugs in aqueous sample using magnetic nanoparticles modified with cetyltrimethylammonium bromide by high performance liquid chromatography. Sci World J 2014;127:8.

8. Chen Y, Guo Z, Wang X, Qiu C. Sample preparation. J Chromatography 2008;1184:191-219.

9. Urraca JL, Aureliano CSA, Schillinger E, Esselmann H, Wiltfang J, Sellergren B, et al. Polymeric complements to the Alzheimer's 
disease biomarker $\beta$-amyloid isoforms $A \beta 1-40$ and $A \beta 1-42$ for blood serum analysis under denaturing conditions. J Am Chem Soc 2011;133:9220.

10. Balogh D, Tel Vered R, Freeman R, Willner I. Photochemically and electrochemically triggered au nanoparticles "Sponges". J Am Chem Soc 2011;133:6533.

11. Hoshino Y, Haberaecker III WW, Kodama T, Zeng Z, Okahata Y, Shea KJ, et al. Recognition, neutralization, and clearance of target peptides in the bloodstream of living mice by molecularly imprinted polymer nanoparticles: a plastic antibody. J Am Chem Soc 2010;132:13648.

12. Yin J, Cui Y, Yang G, Wang H. Molecularly imprinted nanotubes for enantioselective drug delivery and controlled release. Chem Commun 2010;46:7688.

13. Li S, Ge Y, Turner APF. A catalytic and positively thermosensitive molecularly imprinted polymer. Adv Funct Mater 2011;21:1194.

14. Shen X, Zhu L, Wang N, Ye L, Tang H. Molecular imprinting for removing highly toxic organic pollutants. Chem Communications 2012;48:788-98.

15. He CY, Long YY, Pan JL, Li K, Liu F. Application of molecularly imprinted polymers to solid-phase extraction of analytes from real samples. J Biochem Biophys Methods 2007;70:133-50.

16. Anderson RA, Ariffin MM, Cormack PAG, Miller EI. Comparison of molecularly imprinted solid-phase extraction (MISPE) with classical solid-phase extraction (SPE) for the detection of benzodiazepines in post-mortem hair samples. For Sci Int 2008;174:40-6.

17. Garcia R, Cabrita MJ, Freitas AMC. Application of molecularly imprinted polymers for the analysis of pesticide residues in food-a highly selective and innovative approach. Am J Anal Chem 2011;2:16-25.

18. Baggiani C, Anfossi L, Giovannoli C. Solid phase extraction of food contaminants using molecular imprinted polymers. Anal Chim Acta 2007;591:1:29-39.

19. Cacho C, Turiel E, Martn Esteban A, Ayala D, Perez Conde C. Semi-covalent imprinted polymer using propazine methacrylate as template molecule for the clean-up of triazines in soil and vegetable samples. J Chromatography A 2006;1114:255-62.

20. Breton F, Euzet P, Piletsky SA, Giardi MT, Rouillon R Integration of photosynthetic biosensor with molecularly imprinted polymer-based solid phase extraction cartridge. Anal Chim Acta 2006;569:50-7.

21. Hu XG, Hu YL, Li GK. Development of novel molecularly imprinted solid-phase microextraction fiber and its application for the determination of triazines in complicated samples coupled with high-performance liquid chromatography. J Chromatography A 2007;1147:1-9.

22. Turiel E, Martin Esteban A, Fernaindez P, Perez Conde C, Camara C. Molecular recognition in a propazine-imprinted polymer and its application to the determination of triazines in environmental samples. Anal Chem 2001;73:5133-41.

23. Djozan D, Ebrahimi B. Preparation of new solid phase micro extraction fiber on the basis of atrazine-molecular imprinted polymer: application for GC and GC/MS screening of triazine herbicides in water, rice and onion. Anal Chim Acta 2008;616:152-9.

24. Tamayo FG, Casillas JL, Martin Esteban A. Clean up of phenylurea herbicides in plant sample extracts using molecularly imprinted polymers. Anal Bioanal Chem 2005;381:1234-40.

25. Cacho C, Turiel E, Martın Esteban A, Perez Conde C, Camara C. Clean-up of triazines in vegetable extracts by molecularlyimprinted solid-phase extraction using a propazineimprinted polymer. Anal Bioanal Chem 2003;376:491-6.

26. Tamayo FG, Martin Esteban A. Selective high performance liquid chromatography imprinted-stationary phases for the screening of phenylurea herbicides in vegetable samples. J Chromatography A 2005;1098:116-22.

27. Tang KJ, Chen SW, Gu XH, Wang HJ, Dai J, Tang J, et al. Preparation of molecularly imprinted solid phase extraction using bensulfuron-methyl imprinted polymer and clean-up for the sulfonylurea-herbicides in soybean. Anal Chim Acta $2008 ; 614: 112-8$
28. She YX, Cao WQ, Shi XM, Lv XL, Liu JJ, Wang RY, et al. Classspecific molecularly imprinted polymers for the selective extraction and determination of sulfonylurea herbicides in maize samples by high-performance liquid chromatography-tandem mass spectrometry. J Chromatography B 2010;878:2047-53.

29. Zhang L, Han H, Hu YY, Zheng P, Sheng X, Sun H, et al. Selective trace analysis of chloroacetamide herbicides in food samples using dummy molecularly imprinted solid phase extraction based on chemometrics and quantum chemistry. Anal Chim Acta 2012;729:36-44.

30. Baggiani C, Giraudi G, Giovannoli C, Vanni A, Trotta F. A molecularly imprinted polymer for the pesticide bentazone. Anal Comm 1999;36:263-6.

31. Pereira LA, Rath S. Molecularly imprinted solid-phase extraction for the determination of fenitrothion in tomatoes. Anal Bioanal Chem 2009;393:1063-72.

32. Xin JH, Qiao XG, Xu ZX, Zhou J. Molecularly imprinted polymer as sorbent for solid-phase extraction coupling to gas chromatography for the simultaneous determination of trichlorfon and monocrotophos residues in vegetables. Food Anal Methods 2013;6:274-81.

33. Xu ZX, Fang GZ, Wang S. Molecularly imprinted solid phase extraction coupled to high-performance liquid chromatography for determination of trace dichlorvos residues in vegetables. Food Chem 2010;119:845-50.

34. Kang S, Xu Y, Zhou L, Pan C. Preparation of molecularly imprinted polymers diethyl(3 methylureido) (phenyl) methylphosphonate as a dummy template for the recognition of its organophosphate pesticide analogs. J Appl Polymer Sci 2012;14:3737-43.

35. Xie CG, Zhou HK, Gao S, Li HF. Molecular imprinting method for on-line enrichment and chemiluminescent detection of the organophosphate pesticide triazophos. Microchim Acta 2010;171:355-62.

36. Shi XZ, Liu JH, Sun AL, Li DX, Chen J. Group-selective enrichment and determination of pyrethroid insecticides in aquaculture seawater via molecularly imprinted solid phase extraction coupled with gas chromatography-electron capture detection. J Chromatography A 2012;1227:60-6.

37. Zhou JF, Ma C, Zhou S, Ma P, Chen FR, Qi Y, et al. Preparation, evaluation and application of molecularly imprinted solidmicroextraction monolith for selective extraction of pirimicarb in tomato and pear. J Chromatography A 2010;1217:7478-83.

38. Zarejousheghani M, Fiedler P, Möder M, Borsdorf H. Selective mixed-bed solid phase extraction of atrazine herbicide from environmental water samples using molecularly imprinted polymer. Talanta 2014;129:132-8.

39. Feng QZ, Zhao LX, Yan W, Lin JM, Zheng ZX. Molecularly imprinted solid-phase extraction combined with high performance liquid chromatography for analysis of phenolic compounds from environmental water samples. J Hazard Mater 2009;167:282-8.

40. Shen ZL, Yuan D, Su QD, Zhang H, Wang J, Zhu JH, et al. Selective solid-phase extraction using molecularly imprinted polymer for analysis of methamidophos in water and soil samples. Biosci Biotech Biochem 2011;75:473.

41. Qi X, Yang X, Wang B, Yang H, Deng A. Development of a broad selective molecularly imprinted polymers-based solid phase extraction of contraceptive drug levonorgestrel from water samples. Int J Environ Anal Chem 2012;92:268-78.

42. Yu J, X Hu, R Song, S Xi. Molecularly imprinted polymer microspheres prepared by precipitation polymerization for atenolol recognition. Adv Materials Res 2010;148-9:1192-8.

43. Yan H, KH Row. The characteristic and synthetic approach of molecularly imprinted polymers. Int J Mol Sci 2006;7:155-78.

44. Yavuz CT, Prakash A, Mayo JT, Colvin VL. Magnetic separations: fromsteel plants to biotechnology. Chem Engineer Sci 2009;64:10:2510-21.

45. Safarıkova M, Safarık I. Magnetic solid-phase extraction. J Magn Magn Mater 1999;194:108-12.

46. Aguilar Arteaga K, Rodriguez JA, Barrado E. Magnetic solids in analytical chemistry: a review. Anal Chim Acta 2010;674:2:157-65.

47. Sharifabadi MK, Saber Tehrani M, Waqif Husain S, Mehdinia A, Aberoomand Azar P. Determination of residual nonsteroidal 
anti-inflammatory drugs in aqueous sample using magnetic nanoparticles modified with cetyltrimethylammonium bromide by high performance liquid chromatography. Sci World J 2014; $127835: 8$

48. Ibarra IS, Rodriguez JA, Miranda JM, Vega M, Barrado E. Magnetic solid phase extraction based on phenyl silica adsorbent for the determination of tetracyclines in milk samples by capillary electrophoresis. J Chromatogr A 2011;1218: 2196-202.

49. Ibarra IS, Rodriguez JA, Paez Hernandez ME, Santos EM, Miranda JM. Determination of quinolones in milk samples using a combination of magnetic solid-phase extraction and capillary electrophoresis. Electrophoresis 2012;33:13:2041-8.

50. Hu XZ, Chen ML, Gao Q, Yu QW, Feng YQ. Determination of benzimidazole residues in animal tissue samples by combination of magnetic solid-phase extraction with capillary zone electrophoresis. Talanta 2012;89:335-41.

51. Safarik I, Safarikova M. Magnetically modified microbial cells: a new type of magnetic adsorbents. China Particuol 2007;5:19-25.

52. Ibrahim WAW, Nodeh HR, Aboul Enein HY, Sanagi MM. Magnetic solid-phase extraction based on modified ferumoxides for enrichment, preconcentration, and isolation of pesticides and selected pollutants. Critical Rev Chem 2015;45:3:270-87.

53. Li XS, Zhu GT, Luo YB, Yuan BF, Feng YQ. Synthesis and applications of functionalized magnetic materials in sample preparation. TrAC 2013;45:233-47.

54. Huang Y, Wang Y, Pan Q. Magnetic graphene oxide modified with choline chloride-based deep eutectic solvent for the solidphase extraction of protein. Anal Chim Acta 2015;877:90-9.

55. Najafi E, Aboufazeli F, Zhad HRLZ, Sadeghi O, Amani V. A novel magnetic ion imprinted nano-polymer for selective separation and determination of low levels of mercury (II) ions in fish samples. Food Chem 2013;141:4040-5.

56. Pirouz MJ, Beyki MH, Shemirani F. Anhydride functionalised calcium ferrite nanoparticles: a new selective magnetic material for enrichment of lead ions from water and food samples. Food Chem 2015;170:131-7.

57. Aboufazeli F, Zhad HRLZ, Sadeghi O, Karimi M, Najafi E. Novel ion imprinted polymer magnetic mesoporous silica nanoparticles for selective separation and determination of lead ions in food samples. Food Chem 2013;141:4:3459-65.

58. Xiang G, Ma Y, Jiang X, Mao P. Polyelectrolyte multilayers on magnetic silica as a new sorbent for the separation of trace copper in food samples and determination by flame atomic absorption spectrometry. Talanta 2014;130:192-7.

59. Ramandi NF, Shemirani F. Selective ionic liquid ferrofluid based dispersive-solid phase extraction for simultaneous pre concentration/separation of lead and cadmium in milk and biological samples. Talanta 2014;131:404-11.

60. Mashhadizadeh MH, Amoli Diva M, Shapouri MR, Afruzi H. Solid phase extraction of trace amounts of silver, cadmium, copper, mercury, and lead in various food samples based on ethylene glycol bis-mercaptoacetate modified 3-(trimethoxysilyl)-1propanethiol coated $\mathrm{Fe} 304$ nanoparticles. Food Chem 2014;151:300-5.

61. Behbahani B, Salarian M, Bagheri A, Tabani H, Omidi F, Fakhari A, et al. Synthesis, characterization and analytical application of $\mathrm{Zn}(\mathrm{II})$-imprinted polymer as an efficient solidphase extraction technique for trace determination of zinc ions in food samples. J Food Comp Anal 2014;34:1:81-9.

62. Gao Q, Luo D, Ding J, Feng YQ. Rapid magnetic solid phase extraction based on magnetite/silica/poly (methacrylic acidco-ethylene glycol dimethacrylate) composite microspheres for the determination of sulfonamide in milk samples. J Chromatogr A 2010;1217:5602-9.

63. Lan H, Gan N, Pan D. An automated solid-phase microextraction method based on magnetic molecularly imprinted polymer as fiber coating for detection of trace estrogens in milk powder. J Chromatogr A 2014;1331:10-8.

64. Liao W, Chen A, Yang Y. Determination of hindered phenolic antioxidants in plastic packaging injections by magnetic solid phase extraction followed by high performance liquid chromatography. Anal Methods 2015;7:708-15.
65. Huang B, Zhou X, Chen J, Wu G, Lu X. Determination of malachite green in fish based on magnetic molecularly imprinted polymer extraction followed by electrochemiluminescence. Talanta 2015;142:228-34.

66. Mirzajani R, Ahmadi S. Melamine supported magnetic iron oxide nanoparticles (Fe304@Mel) for spectrophotometric determination of malachite green in water samples and fish tissues. J Ind Eng Chem 2015;23:171-8.

67. Sun L, Chen L, Sun X. Analysis of sulfonamides in environmental water samples based on magnetic mixed hemimicelles solid-phase extraction coupled with HPLC-UV detection. Chemosphere 2009;77:10:1306-12.

68. Villaverde JJ, Sevilla Moran B, Lopez Goti C, Alonso Prados JL, Sandin Espana P. Trends in analysis of pesticide residues to fulfil the European regulation (EC) No. 1107/2009. Trends Anal Chem 2016;80:568-80.

69. Shi P, Ye N. Investigation of the adsorption mechanism and pre concentration of sulfonamides using a porphyrinfunctionalized Fe304-graphene oxide nanocomposite. Talanta 2015; 143:219-25.

70. Ye NS, Xie YL, Shi PZ, Gao T, Ma JC. Synthesis of magnetite/graphene oxide/chitosan composite and its application for protein adsorption. Mat Sci Eng 2014;45:8-14.

71. Zhao M, Deng CH, Zhang XM. Synthesis of poly dopaminecoated magnetic graphene for $\mathrm{Cu} 2 \mathrm{p}$ immobilization and application to the enrichment of low concentration peptides for mass spectrometry analysis. ACS Appl Mater Interfaces 2013;5:13104-12.

72. Lu J, Deng $\mathrm{CH}$, Zhang XM, Yang PY. Synthesis of Fe304/graphene/TiO2 composites for the highly selective enrichment of phosphopeptides from biological samples. ACS Appl Mater Interfaces 2013;5:7330-4.

73. Yin P, Sun NR, Deng CH, Li Y, Zhang XM, Yang PY, et al. Facile preparation of magnetic graphene double-sided mesoporous composites for the selective enrichment and analysis of endogenous peptides. Proteomics 2013;13:2243-50.

74. Shi CY, Deng, Li Y, Zhang XM, Yang PY. Hydrophilic polydopamine coated magnetic graphene nanocomposites for highly efficient tryptic immobilization. Proteomics 2014;14:1457-63.

75. Sun NQ, Deng CH, Li Y, Zhang XM. Size-exclusive magnetic graphene/mesoporous silica composites with titanium (IV)immobilized pore walls for selective enrichment of endogenous phosphorylated peptides. ACS Appl Mater Interfaces 2014;6:11799-804.

76. Alvand M, Shemiranil F. Fabrication of Fe304@graphene oxide core-shell nanospheres for ferrofluid-based dispersive solid phase extraction as exemplified for $\mathrm{Cd}(\mathrm{II})$ as a model analyte. Microchim Acta 2016;183:1749-57.

77. Wang $\mathrm{H}$, Yuan $\mathrm{XZ}, \mathrm{Wu} \mathrm{Y}$, Huang $\mathrm{HJ}$, Zeng GM, Liu Y, et al. Adsorption characteristics and behaviors of graphene oxide for $\mathrm{Zn}(\mathrm{II})$ removal from aqueous solution. Appl Surf Sci 2013;279:432-40.

78. Chandra V, Park J, Chun Y, Lee JW, Hwang IC, Kim KS. Waterdispersible magnetite-reduced graphene oxide composites for arsenic removal. ACS Nano 2010;4:3979-86.

79. Zhang YK, Yan T, Yan LG, Guo XY, Cui LM, Wei Q, et al. Preparation of novel cobalt ferrite/chitosan grafted with graphene composite as effective adsorbents for mercury ions. J Mol Liquid 2014;198:381-7.

80. Gollavelli G, Chang CC, Ling YC. Facile synthesis of smart magnetic graphene for safe drinking water: heavy metal removal and disinfection control. ACS Sustain Chem Eng 2013;1:462-72.

81. Zhou G, Xu XY, Zhu WZ, Feng B, Hu JG. Dispersedly embedded loading of $\mathrm{Fe} 304$ nanoparticles into graphene nanosheets for highly efficient and recyclable removal of heavy metal ions. New J Chem 2015;39:7355-62.

82. Chen JH, Xing HT, Sun X, Su ZB, Huang YH, Weng W, et al. Highly effective removal of $\mathrm{Cu}(\mathrm{II})$ by triethylenetetraminemagnetic reduced graphene oxide composite. Appl Surf Sci 2015; 356:355-63.

83. Chen Y, Pan B, Li H, Zhang W, Lv L, Wu J. Selective removal of $\mathrm{Cu}$ (II) ions by using cation-exchange resin-supported 
polyethyleneimine (PEI) nanoclusters. Environ Sci Technol 2010;44:3508-13.

84. Xing $\mathrm{M}, \mathrm{Xu} \mathrm{L}$, Wang J. Mechanism of Co(II) adsorption by zero valent iron/graphene nanocomposite. J Hazard Mater 2016;301:286-96

85. Santhosh C, Kollu P, Felix S, Velmurugan V, Jeong SK, Grace AN, et al. CoFe2O4 and NiFe204@graphene adsorbents for heavy metal ions-kinetic and thermodynamic analysis. RSC Adv 2015;5:28965-72.

86. Qi T, Huang C, Yan S, Li HJ, Pan SY. Synthesis, characterization and adsorption properties of magnetite/reduced graphene oxide nanocomposites. Talanta 2015;144:1116-24.

87. Wang M, Yuan H, Deng W, Bi W, Yang X. A Taiji-principledesigned magnetic porous C-doped graphitic carbon nitride for environment-friendly solid phase extraction of pollutants from water samples. J Chromatogr A 2015;1412;12.

88. Yang J, Si L, Cui S, Bi W. Synthesis of a graphitic carbon nitride for solid phase extraction of phenolic acids. Microchim Acta 2015;182;737.

89. Xu N, Wang Y, Rong M, Ye Z, Deng Z, Chen XJ. Facile preparation and applications of graphitic carbon nitride coating in solidphase microextraction. J Chromatogr A 2014;1364;53.

90. Guan W, Long Z, Liu J, Hua Y, Ma Y, Zhang H. Unique graphitic carbon nitride nanovessels as recyclable adsorbent for solid phase extraction of benzoylurea pesticides in juices samples. Food Anal Methods 2016;8:11-5.

91. Wang M, Yang X, Bi W. Application of magnetic graphitic carbon nitride nanocomposites for the soliphase extraction of phthalate esters in water samples. J Sep Sci 2015;38:445.

92. Zheng HB, Ding JD, Zheng SJ, Zhu GT, Yuan BF, Feng YQ. Facile synthesis of magnetic carbon nitride nanosheets and its application in magnetic solid phase extraction for polycyclic aromatic hydrocarbons in edible oil samples. Talanta 2016;148:46.

93. Dong G, Zhao K, Zhang L. Carbon self-doping induced high electronic conductivity and photoreactivity of g-C3N4. Chem. Commun 2012;48:6178.

94. Zhu Y, Murali S, Cai W, Li X, Suk JW, Potts JR, et al. Graphene and graphene oxide: synthesis, properties, and applications. Adv Mater 2015;35:3906-24.

95. Yin LL, Lin YX, Jia L. Graphene oxide functionalized magnetic nanoparticles as adsorbents for removal of phthalate esters. Microchim Acta 2014;181:957-65.

96. Xiao R, Zhang XT, Zhang XN, Niu JH, Lu MH, Liu XH, Cai ZW, et al. Analysis of flavors and fragrances by HPLC with Fe304@GO magnetic nanocomposite as the adsorbent. Talanta 2017;166:262-7.

97. Han Q, Wang ZH, Xia JF, Chen S, Zhang XQ, Ding MY, et al. Facile and tunable fabrication of $\mathrm{Fe} 304 /$ graphene oxide nanocomposites and their application in the magnetic solidphase extraction of polycyclic aromatic hydrocarbons from environmental water samples. Talanta 2012;101:388-95.

98. Kazemi E, Dadfarnia S, Haji Shabani AM. Dispersive solid phase microextraction with magnetic graphene oxide as the sorbent for separation and preconcentration of ultra-trace amounts of gold ions. Talanta 2015;141:273-8.

99. Sun JP, Liang QL, Han Q, Zhang XQ, Ding MY. One-step synthesis of magnetic graphene oxide nanocomposite and its application in magnetic solid phase extraction of heavy metal ions from biological samples. Talanta 2015;132;557-63.

100. Nazari N, Masrournia M, Eshaghi Z, Bozorgmehr M. Simultaneous extraction and preconcentration of aniline, phenol, and naphthalene using magnetite-graphene oxide composites before gas chromatography determination. J Sep Sci 2016;39:3046-53.

101. Suleiman JS, Hu B, Peng H, Huan C. Separation/ preconcentration of trace amounts of $\mathrm{Cr}, \mathrm{Cu}$ and $\mathrm{Pb}$ in environmental samples by magnetic solid-phase extraction with bismuthiol-II-immobilized magnetic nanoparticles and their determination by ICP-OES. Talanta 2009;77:1579-83.

102. Rezaee M, Yamini Y, Shariati S, Esrafili A, Shamsipur M. Dispersive liquid-liquid microextraction combined with highperformance liquid chromatography-UV detection as a very simple, rapid and sensitive method for the determination of bisphenol a in water samples. J Chromatogr A 2009;1216:1511-4.

103. Rezaee M, Yamini Y, Faraji M. Evolution of dispersive liquidliquid microextraction method. J Chromatogr A 2010;1217:2342.

104. Mashayekhi HA, Abroomand Azar P, Saber Tehrani M, Waqif SH. Simultaneous determination of amphetamine and related compounds in human urine using ultrasound-assisted emulsification microextraction and gas chromatography. Chromatographia 2010;71:517.

105. Barker SA, Long AR, Short CR. Isolation of drug residues from tissues by solid phase dispersion. J Chromatogr 1989;475:35361.

106. Barker SA. Matrix solid phase dispersion (MSPD). J Biochem Biophys Methods 2007;70;151-62.

107. Barker SA. Applications of matrix solid-phase dispersion in food analysis. J Chromatogr A 2000;880:63-8.

108. Barker SA. Matrix solid-phase dispersion. J Chromatogr A 2000;885:115-27.

109. Bogialli S, Di Corcia A. Matrix solid-phase dispersion as a valuable tool for extracting contaminants from foodstuffs. J Biochem Biophys Methods 2007;70:163-79.

110. Moreda Pineiro J, Alonso Rodriguez E, Lopez Mahia $P$, Muniategui Lorenzo S, Prada Rodriguez D, Romaris Hortas V, et al. Matrix solid-phase dispersion of organic compounds and its feasibility for extracting inorganic and organometallic compounds. Trends Anal Chem 2009;28:110-6.

111. Capriotti AL, Cavaliere C, Giansanti P, Gubbiotti R, Samperi R, Lagana A, et al. Recent developments in matrix solid-phase dispersion extraction. J Chromatogr A 2010;1217:2521-32.

112. Capriotti AL, Cavaliere C, Lagana A, Piovesana S, Samperi R. Recent trends in matrix solid-phase dispersion. Trends Anal Chem 2013;43:53-66.

113. Capriotti AL, Cavaliere C, Foglia P, Samperi R, Stampachiacchiere S, Ventura S, et al. Recent advances and developments inmatrix solid-phase dispersion. Trends Anal Chem 2015;71:186-93.

114. Kristenson EM, Ramos L, Th UA, Brinkman. Recent advances in matrix solid phase dispersion. Trends Anal Chem 2006;25:96.

115. Speltini A, Scalabrini A, Maraschi F, Sturini M, Profumo A. Newest applications of molecularly imprinted polymers for extraction of contaminants from environmental and food matrices: a review. Anal Chim Acta 2017;974:1-26.

116. Ashley J, Shahbazi MA, Kant K, Chidambara VA, Wolff A, Bang $\mathrm{DD}$, et al. Molecularly imprinted polymers for sample preparation and biosensing in food analysis: progress and perspectives. Biosens Bioelectron 2017;91:606-15.

117. Wang Y, Chen L. Analysis of malachite green in aquatic products by carbon nanotube-based molecularly imprintedmatrix solid phase dispersion. J Chromatogr B 2015;1002:98106

118. Luo Z, Du W, Zheng P, Guo P, Wu N, Tang W, et al. Molecularly imprinted polymer cartridges coupled to liquid chromatography for simple and selective analysis of penicilloic acid and penilloic acid in milk by matrix solid-phase dispersion. Food Chem Toxicol 2015;83:164-73.

119. Arabi M, Ghaedi M, Ostovan A. Development of dummy molecularly imprinted based on functionalized silica nanoparticles for determination of acrylamide in processed food by matrix solid phase dispersion. Food Chem 2016;210:78-84.

120. Ganan J, Morante Zarcero S, Perez Quintanilla D, Sierra I. Evaluation of mesoporous imprinted silicas as MSPD selective sorbents of ketoprofen in powder milk. Mater Lett 2017;197:5-7.

121. Wang GN, Zhang L, Song YP, Liu JX, Wang JP. Application of molecularly imprinted polymer based matrix solid phase dispersion for determination of fluoroquinolones, tetracyclines and sulfonamides in meat. J Chromatogr B 2017;1065:104-11.

122. De Toffoli AL, Soares Maciel EV, Fumes BH, Lancas FM. The role of graphene-based sorbents in modern sample preparation techniques. J Sep Sci 2018;41:288-302.

123. Zhang BT, Zheng X, Li HF, Lin JM. Application of carbon-based nanomaterials in sample preparation: a review. Anal Chim Acta 2013;784:1-17. 
124. Sun T, Li X, Yang J, Li L, Jin Y, Shi X, et al. Graphene-encapsulated silica as matrix solid-phase dispersion extraction sorbents for the analysis of poly-methoxylated flavonoids in the leaves of Murraya panaculata (L.) Jack. J Sep Sci 2015;38:2132-9.

125. Tan D, Jin J, Li F, Sun X, Dhanjai Ni Y, Chen J, et al. Phenyltrichlorosilane-functionalized magnesium oxide microspheres: preparation, characterization and application for the selective extraction of dioxin-like polycyclic aromatic hydrocarbons in soils with matrix solid-phase dispersion. Anal Chim Acta 2017;956:14-23.

126. Wang T, Chen Y, Ma J, Jin Z, Chai M, Xiao X, et al. A polyethyleneimine-modified attapulgite as a novel solid support in matrix solid-phase dispersion for the extraction of cadmium traces in seafood products. Talanta 2018;180:254-9.

127. Rombaldi C, de Oliveira Arias JL, Hertzog GI, Caldas SS, Vieira JP, Primel EG, et al. New environmentally friendly MSPD solid support based on golden mussel shell: characterization and application for extraction of organic contaminants from muscle tissue. Anal Bioanal Chem 2015;407:4805-14

128. Vieira AA, Caldas SS, Venquiaruti Escarrone AL, de Oliveira Arias JL, Primel EG. Environmentally friendly procedure based on VA-MSPD for the determination of booster biocides in fish tissue. Food Chem 2018;242:475-80.

129. Cao W, Hu SS, Ye LH, Cao J, Pang XQ, Xu JJ, et al. Trace matrix solid phase dispersion using a molecular sieve as the sorbent for the determination of flavonoids in fruit peels by ultraperformance liquid chromatography. Food Chem 2016;190:474-80.

130. Wei M, Chu C, Wang S, Yan J. Quantitative analysis of sesquiterpenes and comparison of three curcuma wenyujin herbal medicines by micro matrix solid phase dispersion coupled with MEEKC. Electrophoresis 2018;39:1119-28.

131. Cao J, Peng LQ, Xu JJ. Microcrystalline cellulose based matrix solid phase dispersion microextration for isomeric triterpenoid acids in loquat leaves by ultrahigh-performance liquid chromatography and quadrupole time-of-flight mass spectrometry. J Chromatogr A 2016;1472:16-26.

132. De Jesus JR, Wanderley KA, Alves Junior S, Navickiene S. Evaluation of a novel metal-organic framework as an adsorbent for the extraction of multiclass pesticides from coconut palm (Cocos nucifera L.): an analytical approach using matrix solidphase dispersion and liquid chromatography. J Sep Sci 2017;40:3327-34.

133. Barreto AS, da Silva Andrade PDC, Farias JM, Menezes Filho A de Sa GF, Alves Junior S, et al. Characterization and application of a lanthanide-based metal-organic framework in the development and validation of a matrix solid-phase dispersion procedure for pesticide extraction on peppers (Capsicum annuum L.) with gas chromatography-mass spectrometry. J Sep Sci 2018;41:1593-9. 